\title{
A violência, entre práticas e representações sociais: uma trajetória de pesquisa
}

Maria Stela Grossi Porto*

A o preparar a apresentação deste dossiê sobre violência, algumas reflexões auxiliaram-me a decidir sobre a forma de conduzi-la. Em primeiro lugar, concluí, com certa apreensão e alguma tristeza, mas também com um sentimento positivo, que este é já o terceiro número de Sociedade e Estado dedicado ao tema. A apreensão e tristeza foram decorrentes da constatação de que, passados 20 anos desde a publicação do primeiro dossiê, em 1995, seguido de um segundo, em 2004, o contexto empírico da violência em suas múltiplas formas de manifestação se mantém como problema social persistente e recorrente - seja em termos das práticas, seja no que diz respeito às representações sociais -, configurando cenários de insegurança e medo que, apesar de diferenças significativas em suas formas de concretização, atravessam o conjunto da sociedade brasileira. O caráter positivo, por sua vez, é consequência da constatação de que, sem se deixar pura e simplesmente colonizar pelos problemas sociais, a reflexão acadêmica soube delimitar quando, como e onde se fazia pertinente construir o problema social como questão sociológica, resultando daí um considerável avanço no processo de conhecimento sobre o fenômeno. Não se pode, por certo, concluir daí que este maior conhecimento resulte automaticamente em menos violência. Mas, também, não é menos verdadeiro que a produção científica da área pode ser - e, eventualmente, tem sido - fonte de subsídio para as políticas públicas de segurança. Ainda que à universidade não caiba instrumentalizar a atuação ou a função da segurança pública, a maior proximidade entre estes campos tem configurado parcerias inexistentes e mesmo impensáveis até há bem pouco tempo, com ganhos e perdas para ambos os lados. Esta realidade acarreta a necessidade de se avaliar e de se questionar, de modo permanente, as possibilidades e os limites de tais parcerias e o sentido destas articulações, não para interrompê-las, mas para aperfeiçoá-las, guardando sempre, com bastante clareza, a distinção entre os objetivos perseguidos pelos campos da ciência e da política. Ou seja, a primeira reflexão contribuiu para reafirmar a importância deste dossiê, que veio complementar, aprofundar e ampliar os temas já abordados nos dois números anteriores da revista.

Em segundo lugar, a reflexão que a seguir ocupou-me intensa e profundamente foi de cunho pessoal e acabou por definir o conteúdo do que vai ser lido: no momento
* Professora titular do Departamento de Sociologia/UnB, Pesquisadora $1 \mathrm{~A}$ do CNPq. Organizadora deste dossiê. <msgrossi@unb.br>. 
mesmo em que me organizava para redigir este texto, coincidência ou não, foi publicado no Diário Oficial o ato de minha aposentadoria. Momento difícil, carregado de ambiguidades, com reações mais ou menos indefinidas, de alegrias e tristezas, de finitude e completude, emoções fincadas na certeza do ontem mais do que na indefinição do amanhã; quase como consequência veio-me o desejo de conduzir esta apresentação de um modo talvez não usual, trazendo um pouco de minha trajetória acadêmica mais recente, ou, para ser mais precisa, evocar o momento em que o tema da violência se insere em minhas reflexões teóricas e nos caminhos empíricos trilhados a partir de então pelas pesquisas empreendidas.

Ao perseguir a concretização deste desejo, retomo, então, indagações passadas, que o tema da violência me suscitou e que continuam a mover minha busca acadêmica atual. Indagações apoiadas e articuladas à utilização da teoria das representações sociais enquanto recurso metodológico para o avanço da pesquisa e do conhecimento sociológico. Proponho-me a uma tarefa que não é fácil. Como ressaltei por ocasião do memorial elaborado para o concurso para professor titular, ao qual recorro seguidas vezes para esta apresentação, fazer essa "estória" é algo próximo a uma psicanálise intelectual, na qual a trajetória acadêmica é passada em perspectiva. Exposição e desvendamento daquele "quem sou eu" da psicanálise, que vai ao fundo do ser em busca da identidade. Filiações, pertencimentos, identificações e oposições a correntes teóricas vão construindo e tecendo tramas em direção a um processo de construção identitária: onde encontro minhas identificações e para onde elas me levam? Lembranças e esquecimentos, alegrias e sofrimentos, angústias e prazeres, distanciamentos e pertencimentos. Não como momentos excludentes, ou dicotômicos, ora uns ora outros desses sentimentos, mas, ao contrário, todos ao mesmo tempo, invadindo nossos espaços, ocupando corpo, coração e mente, tomando por completo o sujeito, a persona que habita cada um de nós no cotidiano profissional.

Minha inserção nesta temática é tardia em termos de temporalidade, se comparada a alguns especialistas da área ou mesmo aos períodos iniciais de minha trajetória, nos quais me ocupei inteiramente da temática rural. A guinada para a reflexão sobre a violência dá-se em meados dos anos 1990, na sequência de uma longa trajetória de trabalho sobre a agropecuária. O aprofundamento do processo de "modernização conservadora" como era então chamado o movimento de penetração do capitalismo no espaço rural brasileiro, acirrou tensões e agravou contradições ligadas à luta pela terra, aos conflitos e à violência. Mortes e violência no campo passaram a ocupar (talvez de forma muito similar ao que hoje ocorre com a violência urbana), não apenas a mídia como ainda o campo científico. Inúmeros foram os trabalhos dedicados à questão da violência no campo; violência física, pela expulsão, aniquilamento e mortes brutais de trabalhadores do campo, violência simbólica - pela 
sujeição a que eram submetidos diferentes segmentos de pequenos produtores rurais - articulada à desqualificação de seu saber, reapropriado pelas grandes empresas agropecuárias em busca de lucros mais significativos. Era um momento de exacerbação das tensões no mundo rural, e se o período foi fértil para a produção acadêmica na sociologia do rural, o mesmo não se deu necessariamente no que dizia respeito a pensar a violência no campo. Algumas análises mantinham-se em um patamar descritivo, nem mesmo chegando à distinção entre conflito e violência, numa clara incorporação, pela sociologia, das categorias empíricas do senso comum, as quais apontavam para o barril de pólvora no qual vinha se transformando o campo brasileiro, segundo distintas avaliações.

Inserindo-me mais intensamente no contexto da violência no espaço rural, dei-me conta de que a sociologia, pressionada pelas demandas da sociedade, pela gravidade do fenômeno das tensões no campo e pelas urgências requeridas por setores distintos da sociedade, sentia-se pressionada a agir. E agia, muitas vezes, através da denúncia. Naquele período, um número considerável de trabalhos acadêmicos ocupou-se em denunciar a violência no campo. Entretanto, com as honrosas e mesmo brilhantes exceções que confirmavam a regra, faltava, por vezes, fôlego teórico a alguns desses trabalhos, cuja preocupação com a denúncia mantinha-os no âmbito da descrição.

Ora, questionava-me, então, se como socióloga não seria urgente ultrapassar o momento, necessário mas insuficiente, da denúncia, criando condições para constituir possíveis "problemas sociais" em questões sociológicas, fazendo avançar as fronteiras do conhecimento. Estava convencida de que só essa ultrapassagem propiciaria o aparato teórico-metodológico para a reflexão, a qual, devidamente munida do instrumental que apenas a ciência propicia, ao somar ou contrapor-se a outras formas de conhecimento, contribuiria para o esclarecimento da ação, subsidiando (ou não) a intervençã $0^{1}$ que outros eventualmente operariam no social. De minha perspectiva, foi fundamentalmente esta insatisfação teórica que fez avançar a reflexão, sobretudo por uma particularidade de natureza conceitual, com a qual se defronta a sociologia e que se prende ao fato de a violência ser e ter se constituído como fenômeno empírico antes de ser construída como conceito teórico. Nessa condição, é apropriada pelo senso comum, pela política, pela mídia e por vários outros campos do saber que não o científico. Em função disso, sua reapropriação, pela sociologia, exige que sejam explicitados os sentidos nos quais é utilizada, de modo a que essa utilização, no interior do discurso científico, adquira força explicativa. Sem tais rupturas reforça-se apenas a dimensão descritiva do trabalho acadêmico, necessária, mas não suficiente.

Ora - alguém poderá dizer - todos os conceitos tiveram trajetórias semelhantes. Entretanto não foi bem o que ocorreu, ao se analisar a trajetória de alguns dos concei-
1. Vários autores já se ocuparam de analisar o contexto da intervenção na análise sociológica. Lembro o texto mais antigo de Elias (1998) e uma reflexão um pouco mais recente de Wieviorka (2007). 
2. Noção então proposta por Tavares dos Santos (1994) para dar conta da complexidade e multiplicidade dos fenômenos sociais aí desenvolvidos. tos clássicos, os quais criaram e organizaram a sociologia, quando de sua fundação como disciplina científica. A título de exemplo, poder-se-ia lembrar o surgimento de conceitos tais como os de anomia, autoridade, estratificação social, poder, classe social, modos de produção e diversos outros: eles construíram o chão teórico-epistemológico da disciplina. No caso da violência, o caminho é, em certo sentido, distinto. Foi a perspectiva empírica que demandou a reflexão e a construção teóricas. E isso exige um cuidado e um distanciamento na tarefa de produção do conceito, como algo que permita avançar na compreensão e explicação do fenômeno. Ter clara a distinção entre os discursos do senso comum e a construção científica é, assim, um primeiro requisito, condição sine qua non para a delimitação do objeto.

Com estas salvaguardas iniciais, coloquei-me desde logo a questão da construção do campo e dos pressupostos teórico-metodológicos para a constituição de uma sociologia da violência e da conflitualidade. Como desafio teórico, colocava-se para mim a tarefa primordial de avançar no conhecimento do estado da arte do tema, condição para avançar igualmente na compreensão e definição sociológicas da violência, fenômeno empírico mutante, já que plural, polissêmico e referido aos valores e à cultura. O desafio metodológico passava pela seleção dos caminhos epistemológicos pertinentes à condução da pesquisa.

Os referenciais estavam ainda ligados à experiência da sociologia rural; as reflexões buscaram aprofundar o conhecimento da produção acadêmica ligada à compreensão dos Processos sociais agrários ${ }^{2}$, e à violência no espaço agrário brasileiro. No contexto internacional, havia tomado contato com os textos de Bourdieu (2002) publicados no periódico Études Rurales e reunidos em um livro intitulado Le bal des célibataires. Fundamentado em pesquisas empíricas realizadas wm Béarn, sua terra natal, sobre o campesinato local e sobre o surgimento de estratégias matrimoniais que se desenvolveram em função da introdução do capitalismo no campo, o autor chega à construção de sua teoria sobre a violência simbólica. Aponta que tais estratégias acabaram por modificar o mercado matrimonial, o qual, antes protegido por regras matrimoniais endogâmicas, e controlado pelas famílias, tornou-se um mercado matrimonial livre, submetido às leis concorrenciais, movimento que eliminou, praticamente sem violência física, um sem número de pequenos produtores rurais, os quais, nessas novas condições, viram seu capital simbólico desmoronar-se, incapazes de competir, neste novo mercado, com os jovens citadinos.

Apesar do interesse em mim despertado naquele momento por tais questões, minhas inquietações, centradas no conhecimento e na busca do espaço teórico de construção de uma sociologia da violência, não afloraram diretamente nos primeiros tempos de pesquisa em sociologia rural, mas foram se sedimentando pouco a pouco, à proporção mesma em que tomava contato com o acirramento da violência no cam- 
po e com o fato de que esta, de algum modo, ganhava mais visibilidade quando das mudanças que se iam processando em decorrência do processo de modernização da agropecuária. De algum modo, os questionamentos oriundos do campo da sociologia rural potencializaram meu interesse em aprofundar a temática da violência, de uma perspectiva mais geral e, sobretudo, buscando seus fundamentos teóricos. Ainda que a violência no campo não tivesse arrefecido (bem ao contrário), meu interesse, cada vez mais, se circunscreveu ao que hoje se denomina violência urbana.

Já inserida na problemática urbana, tomei contato e percebi grande afinidade com o trabalho de Michel Wieviorka (cujo artigo inaugura este dossiê), autor que, ao priorizar o sujeito, em sua condição de ator, realça seu potencial explicativo para as ciências sociais. Enfoque que, em sintonia com a abordagem de Alain Touraine (1984), define o sujeito como sendo a "capacidade de construir-se a si próprio, de proceder a escolhas, de produzir sua própria existência... a capacidade de engajar-se e também de desengajar-se" (Wieviorka, 2006: 203). De forma mais indireta do que direta, entrevejo nesta argumentação afinidades com a perspectiva teórico-metodológica que inspira as reflexões centradas nas representações sociais, como blocos de sentidos presentes nos conteúdos dos discursos e das narrativas dos sujeitos (individuais ou coletivos) a orientar-lhes a conduta.

Ao buscar, uma vez mais, recuperar o período inicial, percebo que a questão das representações sociais colocava-se para mim como uma forma a mais para se pensar as manifestações empíricas do fenômeno da violência. Ou seja, era importante que o esforço de conceituação levasse em conta as representações sobre a violência, distinguindo fenômeno e representação, mas ainda não as concebia como instrumento teórico-metodológico, fato/acontecimento do qual pretendesse utilizar-me analiticamente, como veio a ocorrer logo depois. Ao lado das inquietações teóricas, meus interesses de pesquisa foram, como já dito, se direcionando para o contexto urbano. Interessava-me, cada vez mais, pensar Brasília como locus empírico para pesquisar a violência, já que as demais capitais eram seguidamente objeto de pesquisa e Brasília pouco evidenciada, seja por ser considerada como relativamente pacífica, seja por seu caráter dito de cidade atípica, o que acabava por dificultar sua participação nas composições amostrais que incluíam outras capitais brasileiras. Ao findar dos anos 1990, Brasília veio a se tornar palco do assassinato do índio Galdino Pataxó, fato que inundou a cidade, e o resto do país, através das mais distintas manifestações, incluindo as midiáticas, com um volume considerável de produção de "teorias do senso comum", ou seja, de representações sociais. Representações que buscavam entender e explicar por que jovens de camadas médias e ricas da população (para quem a segurança material e a sobrevivência não se colocavam como problema) podiam ser atores de manifestações tão brutais de violência. Dentre as várias "teorias" assim produzidas, as características de Brasília irrompiam no cená- 
3. Texto que reflete sobre esse caráter atípico de Brasília, do qual, a rigor, discordo, publicado na Sociedade e Estado, em dossiê que organizei sobre representações sociais. rio como possíveis razões, e as ideias de reino de impunidade, ilha da fantasia, terra de ninguém povoavam os meios de massa, impressos e televisivos, levando-me a perceber a importância de se compreender um fenômeno - no meu caso o da violência, através do que é dito sobre ele (Porto, 2009) ${ }^{3}$.

A partir daquele episódio, a análise em termos de representações sociais, "impôs-se" como caminho pertinente para a análise do social; decidi então trilhá-lo, um tanto insegura, já que conhecia pouco do tema, e a sociologia não necessariamente "via com muito bons olhos" (será que já vê?) o fato de se buscar na psicologia social um fundamento metodológico para o trabalho empírico, em uma disciplina que domina métodos e técnicas vistos como tão ou mais pertinentes à prática sociológica. Aventurei-me mesmo assim, acreditando não existir caminho perfeito nem único, e com a intuição (preconceito? em termos durkheimianos) segundo a qual a criatividade e a imaginação sociológicas são, ou deveriam ser, boas conselheiras, aliadas ao conhecimento teórico sólido. A partir de então, passei a explicitar os pressupostos que embasaram, e continuam a fazê-lo, a forma pela qual trabalho com representações sociais e que detalho mais adiante. Funcionam, tais pressupostos, como uma espécie de mode d'emploi, sem, no entanto, funcionarem como livro de receitas.

Nos trabalhos de pesquisa, os dados coletados originam-se de distintas modalidades de coleta de informações, incluindo, entrevistas, questionários, grupos focais, além de pesquisa documental. A título de exemplo, em 1998, dediquei-me a uma grande pesquisa junto à população do Distrito Federal utilizando questionários, num total de 625 respondentes. O questionário, composto de 52 perguntas fechadas, foi organizado em blocos, centrados em conteúdos tais como: violência e cordialidade, violência e legitimidade, violência e direitos, violência e instituições, violência e pobreza, violência e justiça, violência e mídia.

Foram utilizadas perguntas fechadas com o objetivo de captar racionalidades e perceber valores presentes na sociedade sobre o tema da violência; a opção foi estruturar algumas das questões utilizando conteúdos de ditados populares e provérbios (Durkheim, 1971), afirmações do senso comum, chavões e/ou crenças populares presentes, todos eles, na cultura e nas tradições da sociedade brasileira, conforme exemplos a seguir: mulher de malandro gosta de apanhar; homem que é homem não leva desaforo para casa; apanhar na cara e não reagir é sinal de covardia; o brasileiro é um homem cordial; polícia e bandido é tudo a mesma coisa: não pensam duas vezes antes de atirar; homossexualismo é falta de vergonha, tem que ser tratado com pancada; manda quem pode obedece quem tem juízo; justiça é coisa prá privilegiado, pobre é tratado na "marra"; a justiça tarda mas não falha; na falta de uma justiça competente vale a lei do mais forte; as leis existem para serem desobedecidas. 
Em outra pesquisa, os dados foram coletados por meio de entrevistas semiestruturadas e voltadas a segmentos específicos da sociedade; a seleção dos respondentes foi efetuada observando como critério sua relação com a temática abordada. Em casos como este, a preocupação é a de selecionar respondentes "qualificados" no sentido de que possuam conhecimento profissional ou experiência/vivência em relação ao fenômeno abordado, no caso, o da violência.

Também por essa época, ou pouco tempo depois, incorporei em minhas inquietações os conteúdos relativos à temática da polícia e da segurança pública. Essa incorporação decorre do fato de ser impossível buscar-se uma compreensão do fenômeno da violência sem entender os setores e organismos responsáveis pela manutenção de lei e ordem, sabendo-se que, em contextos democráticos, o desafio maior de tal mandato é o de que ele se cumpra na estrita observância dos direitos humanos. Minhas pesquisas atuais, que incluem as corporações civis e militares (mais recentemente também busco incorporar, de modo mais sistemático, a compreensão do Judiciário), priorizam o conhecimento da instituição policial na medida em que, como dito acima, seu bom funcionamento é condição chave para a promoção da segurança e do funcionamento da democracia.

A inquietação mais recente da pesquisa coloca como prioridade refletir sobre as relações entre identidade profissional e violência policial visando, sobretudo, à compreensão mais acurada das relações do policial com a sociedade. Interessa aprofundar as possíveis relações de causalidade entre construção identitária e violência policial. Também por meio de entrevistas, questionários e grupos focais a análise recorre: $a$. às representações sociais que esta categoria (policial) elabora sobre si mesma, enquanto identidade profissional; e $b$. às representações sociais que constroem sobre o outro (ou os outros) com quem se relacionam ou se confrontam em sua prática cotidiana, dentro e fora das fronteiras da própria profissão, como contraponto para pensar e definir o Eu.

Minhas reflexões enfocando violência e segurança pública situam-se na confluência entre função policial e legitimidade. Da perspectiva sociológica, interessa analisar e compreender os contextos nos quais essa legitimidade se converte em seu contrário, passando a ser representada como violência policial e como agressão à população - que o policial deveria, em tese, proteger.

Com base na formulação de Weber (1974; 1991), minha argumentação para trabaIhar o tema sustenta que, se em outros contextos a noção de monopólio carrega em si uma ideia de restrição, quando está em questão a esfera política e a manutenção da ordem, essa restrição nada tem de negativo; ao contrário, apresenta-se como pré-requisito e condição de construção de uma sociedade mais democrática: 
restrito no interior do aparato policial, esse monopólio, em tese, impede a livre circulação da violência e inibe sua existência difusa no conjunto da sociedade, constituindo-se, assim, em condição de pacificação da sociedade. Ao fazê-lo, exclui (também em tese) a violência das formas e práticas quotidianas de interação social, no âmbito da sociedade civil.

No âmbito do Estado, este movimento corresponderia ao estabelecimento do Estado racional-legal tornado possível graças a longos processos de transformação do direito e das formas de administração, substituindo o arbitrário por procedimentos mais igualitários, porque baseados em normas e regras impessoais, universais e racionais (Porto, 1999: 16).

Descumpridas tais condições, abre-se espaço para a violência ilegítima. A missão policial transita, então, nos frágeis limites entre a violência legítima (uso legítimo da força, melhor dizendo), cujo agente é a autoridade policial, e a violência ilegítima como desdobramento dessa mesma autoridade. Em sua discussão sobre as relações entre controle (âmbito do Estado e/ou da sociedade) e autocontrole (âmbito do indivíduo) Elias (1993) é, juntamente com Weber, fonte de inspiração destas reflexões.

Para que esta apresentação possa finalmente atingir mais em detalhe as questões teóricas, algumas especificidades da violência no Brasil poderiam ser ressaltadas para a melhor compreensão do enquadramento teórico e empírico a partir do qual tenho tratado conceitualmente a violência:

1. O fato de, até há pouco tempo, a violência não ter sido nomeada como tal: manifestações violentas eram assumidas como formas rotineiras de regulamentação das relações sociais; eram, além do mais, consideradas, algumas delas, como fenômenos de caráter privado, não sujeitas ao controle público, a exemplo de manifestações de violência ocorridas no âmbito doméstico. Contexto que retardou, por assim dizer, a possibilidade de inserir a violência no rol das categorias explicativas da realidade: o fenômeno não estava todavia construído como objeto de investigação; a sociedade não se espelhava a partir de categorias como a violência; a violência não era nomeada como tal, dificultando sua constituição como objeto sociológico.

2. A ocorrência, ao mesmo tempo, de dois movimentos que pareciam estar em oposição. A tendência, por um lado, de determinados segmentos sociais utilizarem de modo cada vez mais recorrente a violência como forma de resolução dos conflitos. Essa tendência apontaria para um ordenamento social no qual a violência estaria se expandindo do 
âmbito do Estado - instância, que na concepção weberiana, reivindica o monopólio legítimo da força - para o da sociedade civil, caracterizando um movimento de desconcentração desse monopólio. Por outro lado, o surgimento - também mais característico de certos segmentos sociais - de uma maior sensibilidade, significando a recusa de legitimidade a atos de violência, antes considerados "normais", à semelhança do que propõe Wieviorka (1997) ao analisar o contexto francês, e Elias (1993) quando aponta para o desenvolvimento, em paralelo, entre controle e autocontrole. Esse segundo movimento torna-se central para a construção do objeto. Articulado ao processo de redemocratização, que deu visibilidade a contextos que tinham sido vividos até então na obscuridade, trouxe o tema da violência para o centro do debate no âmbito da sociedade e, igualmente, em distintos espaços acadêmicos. Nessa medida, propiciou um avanço da abordagem sociológica voltada ao contexto brasileiro, na medida em que melhor compreender o fenômeno da violência passou a ser, de certa forma, vislumbrado como condição para melhor entender a própria sociedade brasileira. Tal abordagem apela para o reconhecimento do fenômeno em sua existência empírica, nomeia-o como tal, possibilitando, desta forma, construí-lo como conceito, como dispositivo analítico, visando à explicação sociológica ${ }^{4}$. Dessa perspectiva, o esforço de compreensão e definição da violência implica sempre pesquisar, questionar, teórica e empiricamente, a matéria-prima da análise sociológica, isto é, a natureza das relações sociais, uma vez que é nas e pelas relações sociais que o social se constitui como tal, através de condutas significativamente orientadas por um sistema de normas e valores como representação de um dado ordenamento do social, como propõe Weber (1991).

É um esforço que implica, igualmente, a busca de identificação e análise de tipos e formas de violência, e a percepção de suas diferenças, como condição para a construção sociológica. Nesse esforço, a ênfase no aspecto quantitativo, eloquente por si mesma, pode obscurecer aspectos qualitativos ligados à questão, os quais poderiam ser detectados apenas se pensados a partir de uma característica fundamental do fenômeno da violência, que aponta para sua extrema multiplicidade. Em outras palavras, ainda que se possa admitir que a violência apresente um componente difuso, no sentido de que penetra a quase totalidade do tecido social, não é viável pensá-la como fenômeno singular, a se ramificar uniformemente pelo conjunto social. Ao contrário: não existe violência, no singular, mas violências, cujas raízes são múltiplas, e cuja identificação é complexa; portanto, qualquer tentativa explicativa e de conceituação tem que, de forma compulsória, considerar tal multiplicidade. Esse caráter plural do fenômeno é uma constatação relevante; um desdobramento
4. Na condição de dispositivo, lembro a conceituação de Tavares dos Santos (1995), para quem a violência se define como dispositivo de excesso de poder. Sociedade e Estado ( $\mathrm{v}$ X, n. 2, 1995). 
que daí se segue é o de que não sendo singular, mas plural, a violência não pode ser sistematicamente identificada a uma única classe, segmento ou grupo social. Nem a supostos condicionantes territoriais que explicariam sua existência, seja referida à maior incidência em determinados estados do país, seja apontando para sua concentração em espaços específicos, no campo ou na cidade. Ainda nesta direção, associar, com exclusividade, a violência à pobreza, à desigualdade, à marginalidade, à segregação espacial etc., poderia levar a desvendar uma parte importante mas insuficiente da explicação sociológica do fenômeno, já que excluiria, por exemplo, outras manifestações de violência tais como aquelas protagonizadas e sofridas pelas camadas favorecidas e/ou dominantes da população, assim como excluiria, também, certos fenômenos que povoam o imaginário social, produtor e produto de representações sociais da violência.

O esforço no sentido da precisão conceitual leva igualmente em conta a necessidade, incontornável, de considerar aquelas representações produzidas pelos meios de massa, os quais detêm um quase monopólio da informação, levando a situações em que, para numerosos segmentos sociais, o conhecimento da realidade é identificado às informações produzidas pela mídia. O fenômeno da violência pode certamente enquadrar-se nesta situação. Uma complexidade adicional é que a comunicação de massa, a par o bombardeio de informações a que submete o público, mais do que apresentar os fatos "representa" sua versão dos mesmos; "produz" o evento no processo mesmo de edição da notícia, com a consequente "criação" de uma realidade já interpretada, na qual a riqueza dos detalhes é transformada em parâmetro de fidedignidade e a versão representada em sinônimo de única possível. Caminha-se dos fatos aos acontecimentos. Substitui-se o papel de intermediação entre o evento e sua divulgação pela função de produção desse mesmo evento. Nesse contexto de realidades cada vez mais interpretadas, o "olhar" sociológico tem como difícil tarefa construir instrumentos teóricos claros que permitam considerar as relações entre o fenômeno e suas representações, diferenciando igualmente o conceito de suas manifestações empíricas.

Ao aprofundar a reflexão sobre as questões conceituais, torna-se cada vez mais relevante privilegiar a análise do fenômeno da violência a partir dos conteúdos de valores e normas - os quais, na condição de representações sociais, informam práticas sociais e orientam condutas de indivíduos em seu cotidiano, recolocando a função pragmática das representações. Valores e normas que participam da constituição do capital simbólico disponível nas sociedades e que se caracterizam por seu caráter histórico, mutável e plural. O intento de definição não pode, assim, abstrair tais conteúdos.

Da mesma forma, a conceituação do fenômeno da violência implica, necessariamente, distinguir (separar, classificar) diferentes tipos de manifestação da violência. Ainda que sem aprofundar a distinção, já mencionada, entre violência física e 
violência simbólica, valeria lembrar que a subjetividade que caracteriza as dimensões da moral ou do simbólico não elimina o caráter de constrangimento dos atos agressivos ao indivíduo, mesmo na ausência de danos físicos. O que leva a privilegiar uma conceituação mais abrangente do fenômeno que inclua a dimensão simbólica (Bourdieu, 2002; e igualmente sugerido por Yves Michaud, 1989) e conduza a argumentar pela existência de um substrato, ou matriz comum, subjacente à constituição de ambos os mecanismos: tanto aqueles produtores da violência física como os que respondem pela existência da violência simbólica. O que caracterizaria essa matriz seria precisamente a existência de múltiplas lógicas na composição de normas orientadoras de conduta, engendrando graus crescentes, diferenciados e hierarquizados de autonomia, nas práticas dos agentes de um todo social dado. O todo assim constituído adquire sentido como todo fragmentado, autonomizado, múltiplo. Aprofundando um pouco mais características empíricas do fenômeno, as quais se colocam como subsídios para a construção teórica, valeria considerar que determinadas práticas de violência podem visar à afirmação identitária de seus protagonistas por meio da negação de valores e normas societárias vigentes em um movimento de inclusão/exclusão social, que tem nos jovens alguns de seus principais protagonistas e não se restringe a uma camada, classe ou grupo social. Estão aí incluídas práticas que expressam, por vezes, escassa referência a valores "ditos" coletivos e vivenciam situações de redefinição dos conteúdos de sentido orientadores da ação, afirmando valores novos, particulares a determinado grupo, com a consequente negação de conteúdos socializadores, avaliados como universalistas.

Muitas vezes, trata-se de um paralelismo (contiguidade, nos termos de Machado da Silva, 2004), entre lógicas distintas de orientação de condutas. Tal mecanismo organiza (novas?) modalidades de socialização, ou sociabilidade, com apelo a formas violentas de resolução de conflitos (sociabilidade violenta), nas quais as referências valorativas se distanciam dos padrões vigentes, autonomizando-se. A violência pela violência organiza e orienta condutas. Não se trata de uma clássica situação de anomia, mas da coexistência e da convivência (que não implica harmonia) de distintos padrões orientadores de conduta, dentre os quais os portadores de condutas violentas. Ao configurar arranjos societários que são o oposto de situações de homogeneidade social, conformando e estruturando contextos fragmentados, plurais, múltiplos, lança-se mão da violência como recurso disponível, no rol de muitos outros possíveis, como prevê o utilitarismo da teoria da mobilização de recursos. Nessa condição de recurso, a violência se insere em um elenco de estratégias, sua utilização (podendo, ou não, vincular-se a uma hierarquia valorativa) passa a ser questão de eficácia, oportunidade, afirmação de identidades socialmente negadas, explosão de raivas, frustrações, dentre tantas outras possibilidades, com implicações diretas nas formas de representação social do fenômeno. Não apenas novas sociabilidades se estruturam na violência, pois essa pode ainda fundamentar o conteúdo e o substrato 
de representações sociais indicativas da tendência, presente em determinados grupos e camadas sociais, de se utilizar da mesma em diferentes processos de estruturação do social. Como conteúdo, portanto, de novas formas de sociabilidade, conforme argumentação desenvolvida por Machado da Silva, da qual tenho me utilizado com frequência. Reconheço que nem sempre sou completamente fiel à sua teorização quanto ao caráter da "sociabilidade violenta", no sentido de que, para ele, em hipótese alguma está em questão uma luta de valores ou a busca por hegemonia:

A violência urbana está no centro de uma formação discursiva que expressa uma forma de vida constituída pelo uso da força como princípio organizador das relações sociais (Machado, 2004: 58-59).

Concordo, com essa afirmação e com a de que

nas grandes cidades brasileiras, está em adiantado processo de consolidação, no âmbito das rotinas cotidianas, uma ordem social cujo princípio de organização é o recurso universal à força (Machado, 204: 62).

Acrescentaria, como hipótese de trabalho, a merecer difíceis testes empíricos, que, em tese, e sob dadas condições, uma disputa valorativa poderia não ser de todo impossível. Ainda que o contexto brasileiro não tenha, por ora, oferecido nenhuma evidência empírica nessa direção.

Refletir sobre violência a partir desses parâmetros demanda, necessariamente, abrir mão de prescrições normativas e julgamentos de valor, pois o que está em questão, e o que se pretende apreender através da ciência não é o legal ou normativamente correto, mas o efetivamente vigente. Torna-se relevante refletir sobre a ordem em vigor empiricamente na medida em que essa, tanto quanto ou até mesmo mais do que a ordem legal, pode ser reveladora de contextos societários e dos valores neles predominantes. Nesses termos é possível afirmar, por um lado, que a construção do objeto violência, dentro dos pressupostos de uma sociologia compreensiva, supõe integrar momentos de compreensão subjetiva a contextos/situações objetivos; por outro, que perseguir a natureza sociológica da explicação do fenômeno da violência significa encontrar o que é específico (ou típico no sentido weberiano do termo) à análise sociológica, sem que este procedimento implique, no entanto, reducionismo. Em outras palavras, a delimitação da dimensão propriamente sociológica do fenômeno não é sinônimo de negar a existência de outras dimensões da análise, como as que são produzidas no âmbito da psicanálise, da filosofia, da psicologia, da antropologia, entre outras, mas implica precaver-se contra um risco que pode se efetivar, e vem mesmo acontecendo de modo recorrente em algumas explicações do fenômeno: o da "tentação" de assumir a violência como atributo - ou componente 
- constitutivo do ser humano, intrínseco à sua condição. Tal alternativa tem como consequência a naturalização de algo que é socialmente produzido, no interior das ações e relações sociais. Ainda que se possa concordar com analistas que afirmam a inexistência de contextos societários dos quais a violência esteja ausente, tal afirmação não pode significar a negação do componente cultural, ou o desconhecimento de que a natureza humana seja produzida sob a égide da cultura. A busca de melhor compreender - teórica e empiricamente - a violência aponta para uma constatação relevante: se, para outras instâncias explicativas, os componentes da personalidade individual podem ser a chave para o conhecimento das raízes de tal ou qual característica de comportamento, para a análise sociológica, no entanto, precisariam ser considerados, como preconizou Weber (1991), como circunstâncias (como dados), facilitadores ou inibidores de determinadas condutas, sem serem, no entanto, assumidos como explicativos de contextos sociais. Em outras palavras, idiossincrasias pessoais devem ser consideradas, mas não explicam fenômenos sociais.

Do ponto de vista da análise sociológica, abordagens que advogam um caráter fundante e constitutivo para a violência são, no mínimo, paralisantes. Conduzem ao imobilismo teórico. Afirmação que não significa desconsiderar que na existência da violência enquanto realidade empírica, assim como na busca de sua compreensão como objeto de análise, podem interferir fatores de natureza pessoal, política, ideológica e religiosa, entre outros, os quais, não podem ser minimizados quando se está buscando a compreensão da violência.

Pensar em definição quando se trata de um fenômeno tão complexo como o da violência, é pensar em tarefa espinhosa: por um lado, não há, a rigor, uma definição em abstrato, que se "aplique" a qualquer sociedade; por outro, o relativismo não leva a lugar algum. Uma forma possível para sair do impasse seria considerar que o limite para o relativismo estaria dado pela preservação da integridade, física e moral, do indivíduo. Dessa forma, toda vez que tal integridade fosse atingida poder-se-ia assumir a ocorrência de um ato violento. É claro que aí também não se está isento de ambiguidades, uma vez que cabem interpretações distintas sobre a ideia de integridade moral (supondo-se a relativa univocidade do que venha a ser integridade física) e dos critérios para tal classificação. Ao pensar a relação objetivo/ subjetivo, seria viável admitir-se, pelo menos como hipótese operacional, que se poderia falar de violência sempre que a alteridade for "desconsiderada", "esquecida", "desconhecida", "negada". Ou, em outras palavras, haveria violência sempre que o outro fosse desconsiderado como sujeito e, em função disso, tratado como objeto, inviabilizando, em última instância, a interação social, seja ela de natureza consensual ou conflituosa. Violências poderiam, então, ser consideradas como negação da alteridade, lembrando que tal alteridade não se coloca em relação a um sujeito indefinido mas, ao contrário, face a alguém que tem cor, sexo, idade e, ao fazê-lo, 
põe em ação a sujeição criminal de que fala Misse (2008). Não sendo definitiva, ou conclusiva, é uma definição que permite refletir teoricamente e trabalhar empiricamente, reconhecendo o caráter finito, dinâmico e mutante da realidade social e, em consequência, da teoria que reflete sobre ela. Aprofundar conceitualmente e dar argumentos mais substantivos a esta definição é uma questão e um desafio que se recolocam para mim de modo constante, visando à ultrapassagem de uma definição ainda e tão somente operacional, carente de maior consistência teórica.

Da perspectiva metodológica, o conhecimento via representações sociais é um tipo de conhecimento que poderia ser considerado (e assim o tenho chamado) de segundo grau, ou de "segunda mão", não por ser menos relevante do que aquele obtido de "primeira mão", mas na medida em que se chega a ele interrogando a realidade através do que se pensa sobre ela. Exemplificando: ao invés de centrar a análise no(s) dado(s) bruto(s) do fenômeno, interroga(m)-se o(s) imaginário(s) construído(s) sobre o mesmo. É um enfoque que privilegia a linguagem em sua condição de dispositivo analítico, indagando-se sobre que discursos e narrativas são aí produzidos. É a partir dessa dinâmica que tenho procurado entender o fenômeno da violência, ou seja, indagando como a população - em seus diferentes setores, aí incluídos os responsáveis pela segurança pública - "explica" a violência, produzindo "teorias do senso comum" ou elaborando, sobre ela, representações sociais. Quando a violência é capturada pelo viés das representações sociais, o que se coloca como conteúdo para a análise sociológica são os sentidos empíricos, formulados pelo senso comum, permeados por julgamentos de valor e efeitos de hierarquização, que esta categoria carrega, levando o(a) pesquisador(a) a interrogar-se sobre que valores são esses e como tais valores e crenças estruturam e presidem a vida social. Quando consideramos representações sociais como categoria analítica, lidamos com conteúdos valorativos por excelência, pois é desses conteúdos que tais representações se constroem. Trabalhar desta forma significa, em última análise, reinserir a outrora recorrente questão das crenças e dos valores (via análise da linguagem) nos dispositivos postos à disposição da explicação sociológica. O que significa, igualmente, reinserir a discussão acerca do papel e do lugar da subjetividade na teoria, em sua relação com o também recorrente requisito da objetividade, como condição para a produção de conhecimento válido e relevante para a compreensão sociológica.

Assim, crenças e valores são apreendidos em sua condição de princípios orientadores de conduta, tratamento que se aproxima daquele da sociologia compreensiva, perspectiva com a qual, também do ponto de vista metodológico, os argumentos aqui desenvolvidos encontram sua maior identificação.

A apropriação que aqui se faz da teoria de representações sociais, embora guarde uma grande proximidade com a abordagem proposta pela psicologia social, tem, em 
certo sentido, cunho "utilitarista" já que, no percurso empírico em busca dos sentidos presentes em uma dada representação, não percorre passo a passo o caminho daqueles que, na psicologia social, se dedicaram ao tema. Também não privilegia a parte da teoria que se dedica aos aspectos propriamente cognitivos da formação e da constituição das representações sociais e de seus mecanismos de difusão. Além do que, não há, nessa apropriação, a preocupação em dissecar uma dada representação, ressaltando de que modo se constituíram seu núcleo central e suas periferias. Aliás, não distingue centro e periferia. Pelo contrário, trabalha a noção como um todo e sempre no plural, assumindo as representações sociais como blocos de sentido articulados, sintonizados ou em oposição e em competição a outros blocos de sentido, compondo uma teia ou rede de significações apta a permitir avançar no conhecimento da sociedade por ele analisada. Quando se interroga a realidade a partir do que se diz sobre ela, utilizando-se da categoria de representações sociais, assume-se que estas:

a. embora resultantes de experiência individual, são condicionadas pelo tipo de inserção social dos indivíduos que as produzem;

b. expressam visões de mundo objetivando explicar e dar sentido aos fenômenos dos quais se ocupam, ao mesmo tempo em que,

c. por sua condição de representação social, participam da constituição desses mesmos fenômenos;

d. apresentam-se, em sua função prática, como máximas orientadoras de conduta;

e. admitem a existência de uma conexão de sentido (solidariedade) entre elas e os fenômenos aos quais se referem, não sendo, portanto, nem falsas nem verdadeiras, mas a matéria-prima do fazer sociológico (Porto, 2002).

Alguns desses pressupostos relembram ou retomam a questão (que não poderá ser aqui tratada) da relação indivíduo/sociedade. Poder-se-ia afirmar apenas que uma forma profícua para pensá-la seria admitir que indivíduos e sociedade configuram uma relação de mútua interdependência, dialeticamente conflituosa em alguns contextos, relativamente harmoniosa em outros, admitindo também - e sobretudo - que o indivíduo, longe de ser um mero suporte de estruturas, tem que ser considerado em sua condição de agente ou ator, capaz de fazer escolhas e tomar decisões, mesmo que de modo limitado. Postas sob o crivo de tais pressupostos, representações sociais não se situam como ponto de chegada, resultado da investigação, mas constituem-se em pontos de partida, por meio dos quais o investigador começa verdadeiramente sua análise (Porto, 2009). Para assim proceder, utiliza-se, frequentemente, da análise de representações sociais, as quais reafirmam sua re- 
levância ao viabilizarem a consideração das experiências individuais sem secundarizarem o contexto no qual tais experiências são vivenciadas. Seguindo os ensinamentos weberianos,

\begin{abstract}
a interpretação da ação deve tomar nota do fato fundamentalmente importante de que aquelas formações coletivas que fazem parte tanto do pensamento cotidiano quanto do jurídico (ou de outras disciplinas) são representações de algo que em parte existe e em parte pretende vigência, que se encontram na mente de pessoas reais (não apenas dos juízes e funcionários, mas também do "público") e pelas quais se orientam suas ações. Como tais, têm importância causal enorme muitas vezes até dominante para o desenrolar das ações de pessoas reais"(Weber, 1991: 09, grifos do autor).
\end{abstract}

Implícita na formulação encontra-se a ideia de escolha, de seleção que, mesmo inconsciente, informa o agir de atores reais. As representações, de que fala Weber, se constituem em normas jurídicas, valores ou costumes que o ator precisa levar em consideração em seu agir, quer concorde ou não com os mesmos. Ou seja, obedecendo-os ou transgredindo-os. Lendo sem dogmatismo a sociologia weberiana, seria razoável argumentar que, em sua perspectiva, representações coletivas funcionam como situação, condição, ambiente para as ações sociais, podendo facilitá-las, dificultá-las, inviabilizá-las ou apenas se constituírem em um dado. Potencializam, também, a apreensão do caráter fragmentado do social e conduzem a pensar a vigência paralela de ordens contraditórias entre si, assim como a pluralidade e a relatividade dos conteúdos valorativos que demandam do ator escolha e seleção. Razão pela qual a pesquisa não pode se esquivar de interpretá-las se tem pretensões à explicação da realidade social.

Em conformidade com a sociologia weberiana, os fatos empíricos estão constantemente orientados por "ideias de valor". Neste sentido, considera-se apropriado afirmar que o tratamento dado por Weber à questão parece sinalizar, nos moldes de um laisser passer, a relevância de uma abordagem centrada em representações sociais, cujos conteúdos nada mais são do que ideias de valor que uma determinada cultura elabora sobre os fenômenos da vida social e que cabe ao pesquisador desvendar.

Ao considerar tal perspectiva e retomando a articulação proposta entre violência e representações sociais, seria possível admitir que analisar o fenômeno da violência com o instrumento metodológico das representações sociais permitiria descartar definições abstratas; ao fazê-lo, remeteria à relatividade do conceito, a qual tem a ver com a multiplicidade de valores orientadores de conduta e com o fato de que as representações não são independentes do campo social no qual são construídas. 0 
que os atores sociais nomeiam como violência varia segundo as representações que esses se fazem do fenômeno; varia, igualmente, segundo a natureza da sociedade na qual o fenômeno é definido. Sob esse aspecto, quanto mais uma sociedade é unilateral, quanto a suas normas e valores, tanto menos aparece o caráter relativo do conceito e tem-se a ilusão de objetividade, construída por uma suposta unidade de pontos de vista. Sociedades mais plurais convivem com uma multiplicidade normativa, coexistindo lado a lado ou disputando hegemonia.

Para aprofundar essa linha de raciocínio, existiriam, por um lado, contextos (objetivos) mais ou menos favoráveis ao desenvolvimento da violência; por outro, o que é representado como violência (dimensão subjetiva) "participa" igualmente da realidade da violência.

No sentido de enfeixar os pressupostos que explicitam os caminhos teórico-metodológicos de recepção da Teoria das representações sociais, poder-se-ia concluir afirmando que representações sociais não são nem racionais nem irracionais; são existenciais, ontológicas e respondem por uma lógica e uma racionalidade que as constituem em objeto do conhecimento e da análise sociológica, para serem compreendidas mais até do que só explicadas. E isto à condição de que sejam assumidas pelo que de fato são: substrato material, sinal externo, vida cristalizada (Durkheim, 1971). Sua racionalidade é de natureza totalmente distinta daquela proporcionada pelo conhecimento da ciência. Para o analista do social, se é pertinente buscar as relações entre o fenômeno e suas representações, não é por considerar que as últimas sejam sinônimo do real, falsas ou verdadeiras, e sim por assumi-las como um dado bruto da realidade, matéria-prima da tarefa de investigação que precisa ser submetida ao crivo da ciência, como condição de produção de um conhecimento pertinente.

A terceira e última reflexão, finalizando esta apresentação, retoma o comentário inicial acerca do formato dado ao texto, quando apresentei as razões que orientaram a direção a tomar. Acrescento agora a última destas razões: ao propor o dossiê, optei deliberadamente por consagrá-lo ao tema da violência de um modo geral e abrangente, de forma a não restringir, demasiadamente, com um subtítulo, o caráter das contribuições, as quais poderiam tomar, como de fato o fizeram, trilhas teóricas ou empíricas as mais diversas. Esta escolha trouxe enorme riqueza ao dossiê, que se caracteriza por conteúdos teóricos e empíricos em um leque que privilegia a perspectiva sociológica mais ampla e, a partir daí, traz a questão da violência em suas manifestações específicas; mas também contempla o percurso inverso: aponta os desafios postos pelos dados e pelas evidências empíricas sendo construídos como objetos teóricos por meio da busca por compreensão dos sentidos de lei, da ordem, da segurança pública. Neste pêndulo entre o teórico e o empírico afloram 
temas como os da subjetivação e dessubjetivação, da crueldade, da pobreza, da juventude. Da mesma forma, os textos são construídos com referência a contextos nacionais tanto quanto internacionais: África, França, México, Canadá e Brasil fazem parte do pano de fundo que alimentou a reflexão dos participantes do dossiê.

Gostaria de agradecer aos(as) pesquisadores(as) que participaram deste dossiê pela disponibilidade, pela criatividade e pela competência das contribuições. A qualidade do número é fruto de cada um destes artigos. Infelizmente, nem todos(as) que se dedicam ao tema estão presentes. Alguns(as) não tiveram condições de participar; outros(as) tinham já contribuído nos dois números anteriores; por último, tivemos que nos conformar aos limites impostos pelas normas da revista que restringe em até cinco o número de artigos por dossiê. Desse modo, nem todas as formas, faces e manifestações do fenômeno foram aqui contempladas. Neste caso, como comentado nos números precedentes dedicados ao tema, as lacunas funcionam como desafio para que novos dossiês, com outros matizes e matrizes sejam propostos e organizados, com a perspectiva de que possam anunciar mundos mais solidários e formas viáveis de saídas para a violência; com esperança sim, mas sem idealismos que impeçam de olhar o futuro com os olhos mergulhados na contemporaneidade e no que ela requer hoje da imaginação sociológica.

\section{Referências}

DURKHEIM, Émile. As regras do método sociológico. 6. ed. São Paulo: Compahia Editora Nacional, 1971.

ELIAS, Norbert. Envolvimento e alienação. Rio de Janeiro: Bertrand Brasil, 1998.

O processo civilizador. Rio de Janeiro: Jorge Zahar Editores, 1993.

BOURDIEU, Pierre. Le bal des célibataires. Crise de la société paysanne en Béarn. Paris: Seuil, 2002.

GIDDENS, Anthony. A constituição da sociedade. São Paulo: Martins Fontes, 2003.

MACHADO DA SILVA, Luis Antônio. Sociabilidade violenta: por uma interpretação da criminalidade contemporânea no Brasil urbano. Sociedade e Estado, v. 19, n. 1, Jan./Jun. 2004.

MOSCOVICl, Serge. Representações sociais - investigações em psicologia social. Petrópolis: Vozes, 2003.

Das representações coletivas às representações sociais: elementos para uma história. In: JODELET, Denise (Org.). As representações sociais. Rio de Janeiro: Editora da Uerj, 2001. 
MICHAUD, Yves. A violência. São Paulo: Ática, 1989.

MISSE, Michel. Sobre a construção social do crime no Brasil: esboços de uma interpretação. In: MISSE, Michel (Org.). Acusados e acusadores. Rio de Janeiro: Revan, 2008.

PORTO, Maria Stela Grossi . Entre a política e a religião: caminhos da contribuição weberiana à análise da violência. Sociologias, Ano 1 n. 1, p. 14-33, Jan./Jun. 1999.

Violência e meios de comunicação de massa na sociedade contemporânea. Sociologias, Ano 4, n. 8, p. 152-171, Jul./Dez. 2002.

Brasília, uma cidade como as outras? Sociedade e Estado, v. 24, n.3, p. 797826, Set./Dez. 2009.

TAVARES DOS SANTOS, José Vicente. Por uma sociologia dos processos sociais agrários. Cadernos de Sociologia PPGS/UFRGS, Porto Alegre, 1995.

A Violência como dispositivo de excesso de poder. Sociedade e Estado, v. 10, n. 2, 1995.

TOURAINE, Alain. Le retour de l'acteur. Essai de sociologie. Paris: Fayard, 1984.

WEBER, Max. A política como vocação. In: WEBER, Max. Ensaios de sociologia. 3. ed. Rio de janeiro: Zahar Editores, 1974.

A objetividade do conhecimento nas ciências sociais. In: CONH, Gabriel (Org.). Weber - sociologia. Coleção "Grandes cientistas sociais". São Paulo: Ática, 1986.

Economia e sociedade - fundamentos da sociologia compreensiva. Brasília: Editora UnB, 1991.

WIEVIORKA, Michel. Em que mundo viveremos? São Paulo: Perspectiva, 2006.

O novo paradigma da violência. Tempo Social, v. 9, n. 1, Maio 1997.

- Introduction. In: WIEVIORKA, Michel (Org.). Les sciences sociales em mutation. Paris: Éditions Sciences Humaines, 2007. 